\title{
Market Opportunity in Computational Proteomics
}

\author{
Enal Razvi \\ Vice President, Business Development, DiscoveRx Corporation, Fremont, CA, USA
}

Computational Proteomics Supplement 32:S54-S62 (March 2002)

\section{SUMMARY}

The current exuberance on the potential of proteomics as a means to deploy the wealth of the human genome is expected to last into the coming years. Unlike the genome, a finite entity with a fixed number of base pairs of the genetic material, the proteome is "plastic", changing throughout growth and development and environmental stresses, as well as in pathological situations. Our proteomes change over time, and therefore there is no one proteome; the proteome is for practical purposes an infinite entity. It is therefore crucial to build systems that are capable of manipulating the information content that is the proteome, thence the need for computational proteomics as a discipline.

In this MarketView article, we present the industry landscape that is emerging in the computational proteomics space. This space is still in its infancy and for the most part undefined; therefore we seek to present the market opportunity in informatics in the drug discovery space and then extend that to an examination of industry trends in proteomics. Thus, the gestalt is a set of predictions as to the evolution of the landscape in computational proteomics over the coming years.

\section{INTRODUCTION}

The fundamental impact of the biotechnology industry is the realization that the technology and talent of drug discovery has moved outside the confines, and conformity, of big pharma. Replacing the fully integrated pharmaceutical company (FIPCO), there is now an ecology of small, venture-funded start-ups working in what a decade ago would have been an internal function. This market change generates new levels of scientific interest and commercial visibility.

In response, big pharma is looking to either copy this trend to capture its vitality (for example GlaxoSmithKline's [GSKs] new re-organization of discovery around self-contained biotech clusters $^{1}$ ) or to establish internal venture capital funds to capitalize on the innovation.

The key issue in moving from the FIPCO 2 to the ecology of the biotech industry is the fragmentation of the infrastructure.
Whereas there is some evidence that the essential creativity and innovation comes from small groups and focused organizations, this potential is easily lost if these small companies are under-resourced and under-equipped. Automation and miniaturization have significantly reduced the cost of research-for example, a gene sequence that once took laboratory full of chemists to analyze is reduced to a few dollars per sample when analyzed through an automated device.

\section{THE PROBLEM OF THE BIOLOGICAL DATA EXPLOSION}

Scientifically the challenge facing all biopharma research is the rapid expansion of the data and information infrastructure to cope with the flood of data emerging from the new sciences, such as genomics, and the new automation in high-throughput screening (Exhibit 1).

Bioinformatics, and its companion chemi-informatics, are now key components of the discovery infrastructure of biopharma companies (Exhibit 2).

In practical terms the technology is leading to a significant re-design of the early stage processes of large and mid-range pharma. A recently presented example ${ }^{4}$ from a large pharmaceutical company indicates the change in the pipeline and the extent of the commercial partnerships necessary to meet this challenge (Exhibit 3).

\section{BUSINESS MODELS IN LIFE SCIENCE INFORMATICS}

The key problem remains that the market for bioinformatics, at least as originally conceived, isn't large enough to support a company built around one or two high-cost software programs targeted to a relatively small user group 5 .

As we assess the market or potential market of bioinformatics we must consider the strategies effective to reach different, or all, parts of the potential market - strategies focused at the high margin big pharma market (limited in opportunities) or strategies designed to embrace all biological scientists (at a reduced or

\footnotetext{
${ }^{1}$ Yamada stokes the boiler in GSK's engine room article by David Pilling, Financial Times; February 22, 2001.

2 Modern Strategy for Preclinical Pharmaceutical R \& D: Towards the Virtual Research Company; by David Cavalla, John D. Flack, and Richard Jennings; John Wiley \& Sons; ISBN: 0471971170.

3 Pfizer Analysts Meeting, December 2000.

${ }^{4}$ Executive Case Study: A Big Pharma Research Platformpresented to Eye for Pharma East 2001 Business in the Post Genomics Era, by Prof. Dr. Wolf-Dieter Busse of

Bayer, Germany.
5 Start Up, Windhover, January 2000.
} 
variable margin). The income envelope for a supplier in these markets is illustrated in Exhibit 4.

To develop the potential market there is a clear choice for bioinformatics vendors between a strategy that focuses on large pharma (with a high cost, high cost of production, and restricted market) and one that embraces all life scientists (with a lower cost but expanded market).

However this market choice is not just about the cost of the product and the direct sale market, but also about the value proposition. As big pharma looks to the biotech and start-up markets for innovation, so bioinformatics, if it is to be part of this innovation and hence value proposition, has to re-position itself, moving to embrace smaller organizations.

\section{VALUING THE MARKET OPPORTUNITY IN INFORMATICS IN THE LIFE SCIENCE SPACE- COMPUTATIONAL PROTEOMICS AS A SUBSET}

\section{Hyperbole}

Computer code, according to Bill Joy, chief scientist at Sun Microsystems, is now having more impact on the biological sciences than traditional exploration techniques, like examining tissue sant ples. "It is symbolic that the code of the human genome has been broken in the year 2000. It has made biology into an information science. The 21st century is going to be the real information age, and I don't mean the Internet.

"The upside is enormous. Over the course of the next century, it can create USD 1,000 trillion in new wealth, "he told the Forum, according to Reuters. Paul Saffo, director of the Institute for the Future, said: "The biggest surprise is perhaps that we are at the inter- section of the two [biotechnology and computing]."

It's no coincidence that Larry Ellison and Craig Venter share a passion for both biology and information sciences. These once-separate domains are flowing together in a union that could change the whole geography of high technology-and lead to a $\$ 43$ billion market by 2004 . On one side, the tsunami of information generated by the Human Genome Project is forcing drug companies to retool themselves as information brokers. Their survival will depend on finding new ways to spin gene data into blockbuster drugs 6 .

\section{Defining The Market ${ }^{7}$}

The modeling and simulation market is about $\$ 100$ million. The chemoinformatics and bioinformatics markets are really very new and are growing rapidly. They're estimated to be in the $\$ 100$ million range and there are projections that they will grow to several billion dollars over the next 10 years ${ }^{8}$.

The worldwide bioinformatics market is mostly localized in the United States and Europe. The market value of products and services is valued at over US\$2 billion. Predominantly, there are two application areas - ag-bio and pharmaceuticals (drug discovery). While agricultural bioinformatics depends on the whole genome sequencing of plants, the pharmaceutical sector relies on the success of the Human Genome Sequencing efforts along with the sequencing of the mouse and other model organisms for comparative genomic efforts and for clinical trials in model organisms, as well as proteomics.

Given the nascent nature of this industry and the large num ber of private players in the field, the current market for external products and services is hard to determine. Surveys of the 50 or so bioinformatics tool and database companies by market re-

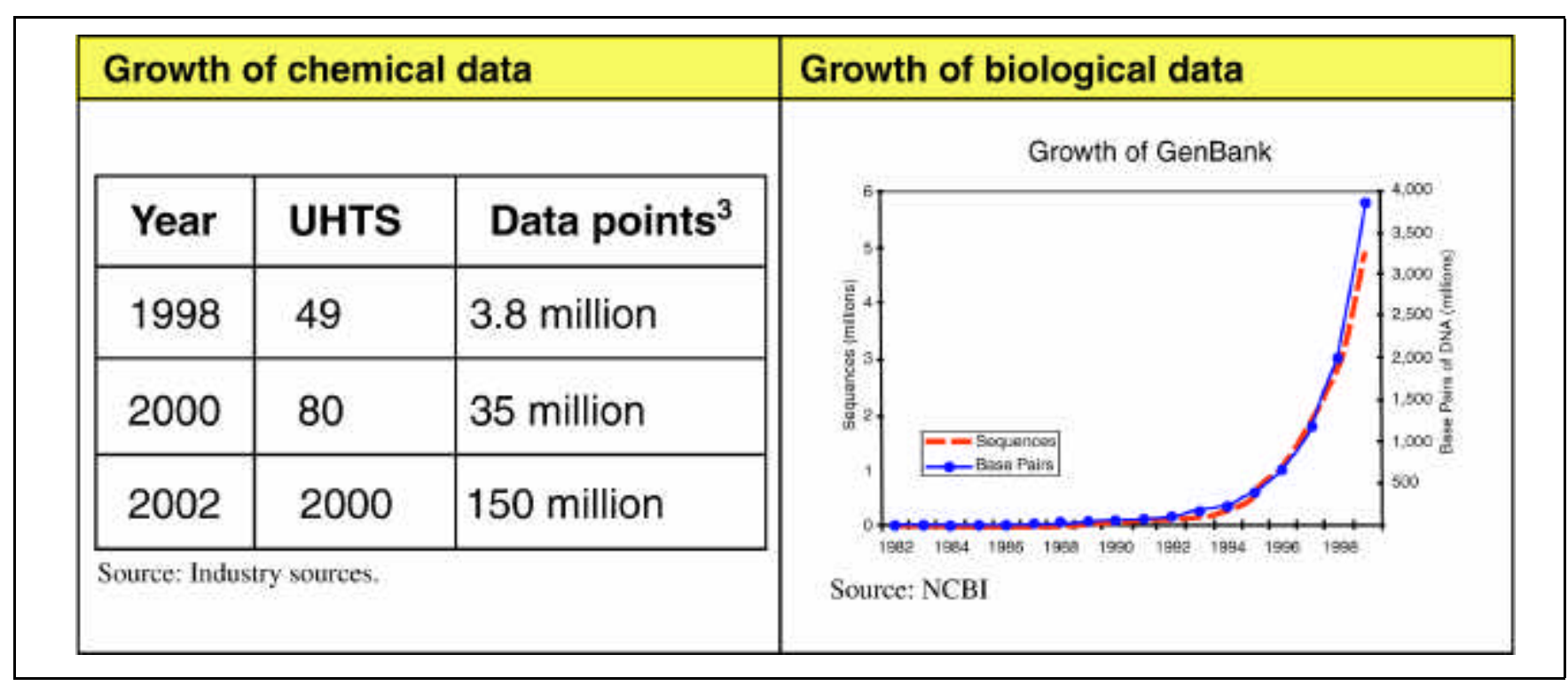

Exhibit 1. Life science data explosion. UHTS, ultra high-throughput screening.

\footnotetext{
${ }^{6}$ Business Week; April 3, 200; BusinessWeek 50 BIOINFORMATICS; Copyright 2001, The McGraw-Hill Companies, Inc.

7 Derived from Maturing Business Models Using Genomics Data, by Michael Lytton, Start-Up January 2001, Windhover.

8 Joseph A. Mollica is Chairman, President and Chief Executive Officer of Pharmacopeia, Inc., quoted in The Wall Street Transcript.
} 
search groups like Frontline and Frost \& Sullivan, for example, put the current market for bioinformatics databases, products, and services at roughly $\$ 300$ million $^{9}$, with about half of the annual sales by data suppliers and half of the sales by tool/IT providers of various kinds.

These groups and other industry observers believe that this market could grow to $\$ 1.5-2.0$ billion over the next five years. These estimates exclude some significant internal spending on IT infrastructure by pharmaceutical and biotechnology companies that is bioinformatics related, and could be as large as $\$ 2.0$ billion+ annually. As discussed above, also excluded are most of the project-based $\mathrm{R} \& \mathrm{D}$ collaborations between "pharma/agbio" companies and genomics companies that include bioinfor-

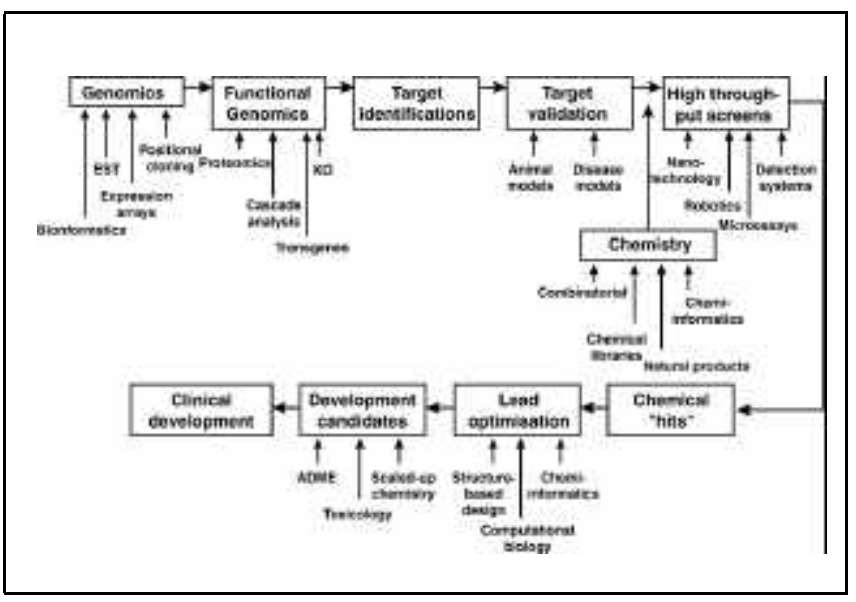

Exhibit 2. Bioinformatics and chemi-informatics (Source: Enal Razvi, PhD). matics "content" and which total well over $\$ 1.0$ billion on a cumulative basis over the past 3 to 5 years.

More recently Silico Research Ltd. has produced an analysis on the market size based upon extensive interviews with biopharma companies. Their estimates are presented in Exhibit 6.

Nat Goodman has also referenced the current market of “ $\$ 200 \mathrm{M}$ " in his recent article ${ }^{10}$. These estimates are amplified in the recent report by Oscar Gross ${ }^{11}$ which speculates that an increasing proportion of the informatics spend of biopharma research will be outsourced 12 . As discussed above, also excluded are most of the project-based $\mathrm{R} \& \mathrm{D}$ collaborations between pharma/ag-bio companies and genomics companies that include bioinformatics content.

\section{MARKET OPPORTUNITY OF INFORMATICS BASED ON ITS IMPACT ON R\&D}

The recent Lehman/McKinsey report The Fruits of Genomics $^{13}$ suggests that the vast array of new targets made possible by the genomics revolution ${ }^{14}$ will initially demand a high and costly attrition through the clinical process. This increased development expenditure will, unabated, limit the companies capable of bringing product to market and strangle the early stage investment. This rather dismal prospectus paints a gloomy midterm forecast for biotechs (with limited development resources) and narrowly focused (small) pharma companies.

Using the Lehman figures - the entry cost to genomics is $\$ 100$ million annual spending which, using industry averages, means a total R\&D budget of $\$ 500$ million or sales of $\$ 2.5$ billion. This limits genomics to 39 companies or 23 qualified by an R\&D budget exceeding $\$ 500$ million 15 .

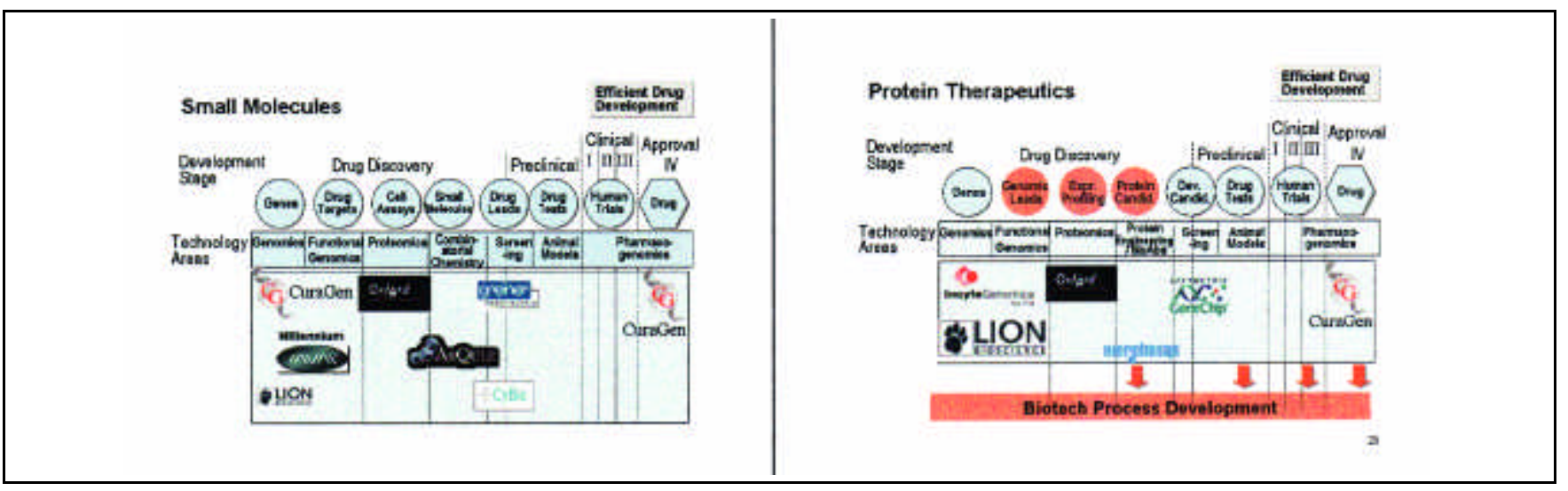

Exhibit 3. Bioinformatics integrated into discovery (Source: Industry sources).

\footnotetext{
${ }^{9}$ Such industry surveys have their dangers. For example some sources suggest there are $290+$ companies with bioinformatics products, compared with the 50 chosen by Frost $\&$ Sullivan. Also the survey frequently looked at publicly quoted or venture-funded organizations, but much bioinformatics development is privately funded as is the case for MatrixScience (private communication, John Cottrell).

10 Who Wants to be a Bioinformatics Millionaire, Genome Technology, May 2001.

11 Trends In Commercial Bioinformatics, by Oscar Gross; Biotechnology Review, March 13, 2001.

$12 \$ 5.6$ billion of the $\$ 14$ billion ( $40 \%$ ) spend on discovery is outsourced.

13 The Fruits of Genomics, referenced in Chemical Reporter, March 12, 2001, p. 31.

14 Quo vadis, biotech? Jurgen Drews in Drug Discovery Today, Vol. 5, No. 12, December 2000.

15 Pharmaceutical Business, December 2000 list of top 50 companies with a revenue in excess of $\$ 2.5$ billion.
} 
The Lehman report goes further by estimating informatics costs at $30 \%$ of genomic research costs (multiplying through these figures represents $7 \%$ of R\&D or $1.5 \%$ of company revenue). Given that the total informatics costs inevitably include "IT for knowledge workers"-email, office, and productivity tools-a good optimistic estimate would be $5 \%$ of R\&D or $1 \%$ of revenue. Of this it would be prudent to eliminate the internal effort (generally $30 \%$ of $R \& D$ is outsourced but we can probably increase this to $50 \%$ for bioinformatics), there are arguably reductions from the total informatics costs that are not bioinfomatics from specialist IT areas such as data collection.

So the estimates based on value are: $1 \%-3 \%$ of $R \& D$ spend-

\section{The Market Economics}

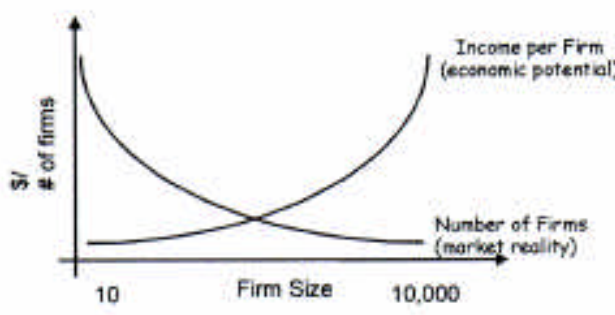

Big Pharma

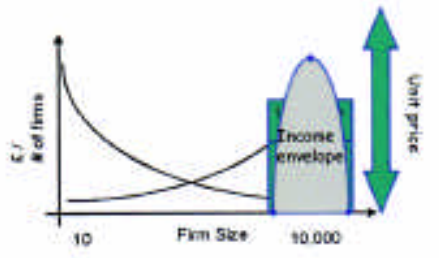

\section{Pharma plus biotech}

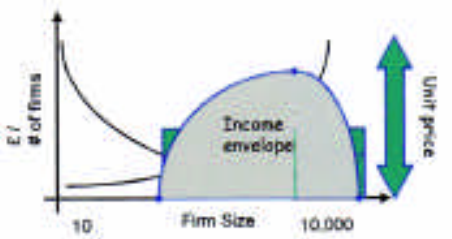

Pile high, sell cheap

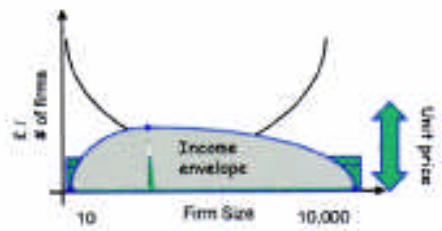

Exhibit 4. Life science informatics market models (Source: Industry sources).

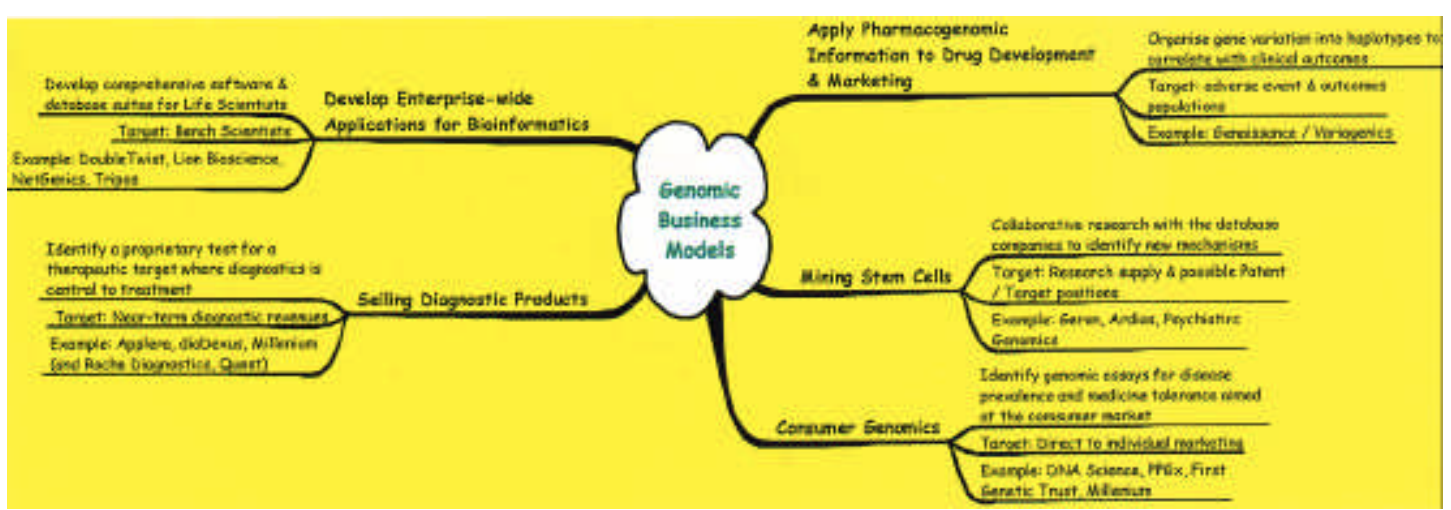

Exhibit 5. Genomics business models (Source: Windhover). 
ing, which for the top 24 companies (in R\&D) with a combined expenditure ${ }^{16}$ of $\$ 38.6$ billion is between $\$ 300$ million to $\$ 1$ billion 17 .

Of course all of these estimates must inevitably overestimate the bioinformatics market because they assume the source of new products (and hence focus for research) is exclusively new chemical entities (NCEs) unveiled by genomics. It ignores the product extension work (around the existing NCEs), the fast followers (the current equivalent of analog bashing but with a known target and/or mechanism), the traditional targets (such as G-protein coupled receptors [GPCRs]) and the drug delivery work. Of course the protagonists of genomics forecast a faster take-up of genetic technologies but these predictions are as yet to reach commercial reality (Exhibit 7).

More appropriately the impact of genomics should be considered against its impact on the research activity across different therapeutic areas. The figures vary by medical intervention but display the same general characteristics 20 (Exhibit 8).

Factoring the potential market by the contribution of genomics to new product discovery provides a market value for life science informatics focused upon drug discovery driven by the genomics (and the emerging proteomics paradigm), between $\$ 150$ million and $\$ 500$ million, worldwide.

\section{THE EMERGING PROTEOMICS PARADIGM}

In the previous sections of this MarketView article we exam ined the quantitative market opportunity in the life science informatics space specifically created by the genomics paradigm. Included therein, albeit a small fraction, is the market for com putational tools in proteomics. We focus here on the qualitative market opportunity for computational proteomics afforded by the excitement around proteomics as a discipline.

Exhibit 9 presents the continuum of proteomics as it is unfolding in the biopharma community.

Note that this continuum is composed of the structural proteomics elements-i.e., protein structure and interactions in vitro, as well as the more downstream signaling elements and in vivo protein-protein interactions that are the domain of functional proteomics. Most of the companies in the proteomics space are currently focused upon the structural proteomics paradigm; a very small number have begun to address the future bottlenecks in unraveling protein biology in the in vivo milieu.

Every element of the proteomics discipline-from protein identification through to in vivo protein pathway analysis-is driven by the genomic data and reagents that have been assem bled over the course of the past several years. The role of the genomics enterprise was to identify sequences and polymorphisms, as well as reagents that could be used to characterize biology at the molecular level. Every aspect of proteomics now draws upon these data and reagents from proteomics to assem ble the dynamic state of biology (both normal physiology as well as pathological situations).

Exhibit 10 presents a schematic of the pre- and post-genom ic/proteomic state of the biopharma industry in order to spot-

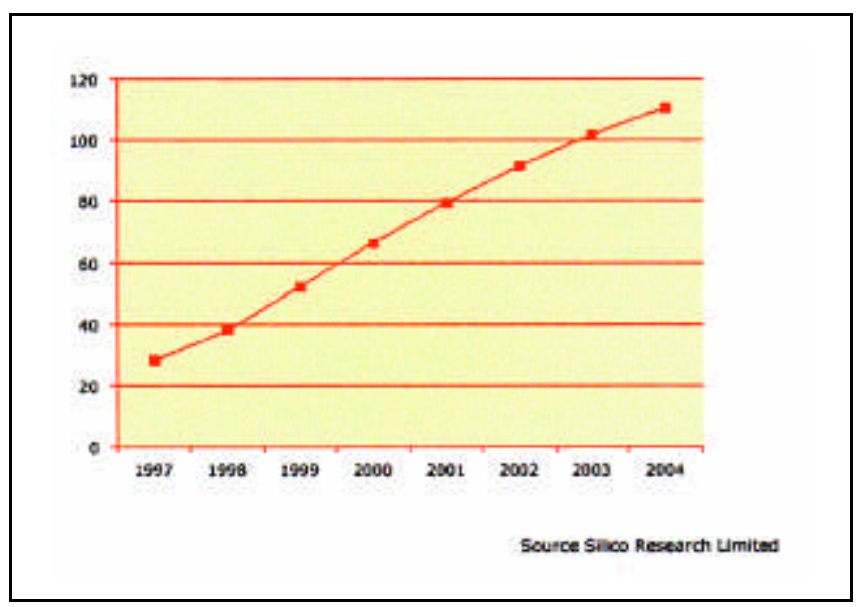

Exhibit 6. Worldwide bioinformatics revenues (US\$, Millions)

\begin{tabular}{|ccc|}
\hline Year & $\begin{array}{c}\text { Market } \\
\text { Value }\end{array}$ & $\begin{array}{c}\text { \% of Total } \\
\text { Market }^{19}\end{array}$ \\
\hline 2005 & $\$ 500 \mathrm{M}$ & $0.2 \%$ \\
2010 & $\$ 10 \mathrm{~B}$ & $3 \%$ \\
2015 & $\$ 25 \mathrm{~B}$ & $8 \%$ \\
2020 & $\$ 50 \mathrm{~B}$ & $16 \%$ \\
\hline
\end{tabular}

Exhibit 7. Market forecast for genomic-based therapies (Source: Industry sources).

\begin{tabular}{|lcc|}
\hline Therapy Area & $\begin{array}{c}\text { Share of } \\
\text { Genomics 20000 } \\
\text { (\%) }\end{array}$ & $\begin{array}{c}\text { Share of } \\
\text { Genomics 2005 } \\
\text { (\%) }\end{array}$ \\
\hline Central Nervous System & 20 & 40 \\
Cardiovascular Diseases & 25 & 30 \\
Autoimmune Diseases & 15 & 30 \\
Infectious Diseases & 20 & 55 \\
Metabolic Diseases & 25 & 40 \\
Cancer & 25 & 50 \\
\hline
\end{tabular}

Exhibit 8. Genomic impact by therapeutic area (Source: Industry sources).

\footnotetext{
${ }^{16}$ Compared with top 25 biotechs $R \& D$ of $\$ 3.5$ billion in R\&D.

${ }^{17}$ Incidentally, the next 24 companies only contribute an additional $\$ 7$ billion of R\&D expenditure - so even if the "critical mass" argument by Lehman is wrong, the market size is not much more than this.

18 Source Datamonitor.

${ }^{19}$ As a "rule of thumb", the contribution of genomic techniques in discovery pre-dates the impact on the market by a decade. Typically to achieve a $16 \%$ market share in 2020 we should assume $16 \%$ of discovery targets are derived from genomic techniques in 2010.

20 Parexel Pharmaceutical R\&D yearbook, 2001.
} 


\section{MARKETVIEW}

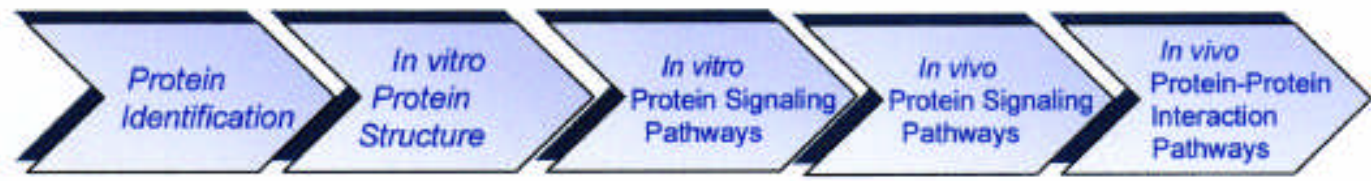

Exhibit 9. The continuum of proteomics (Source: Enal Razvi, PhD).

\begin{tabular}{|c|c|c|c|c|c|}
\hline 1980 & & 990 & 2000 & & 2010 \\
\hline Pre-C & mics & Gen & omics/Prot & teomics & \\
\hline & & Foundation & & Function & Fruition \\
\hline Genome Sequence: & NO & & YES & YES & YES \\
\hline Genes Known: & $<1000$ & & 15,000 & 30,000 & 30,000 \\
\hline Targets: & $<500$ & & $500-1000$ & 4,000 & 8,000 \\
\hline Sales of Genomics Drugs: & $<\$ 5 b$ & & $<\$ 20 b$ & $>\$ 30 b$ & $\$ x \times x b$ ? \\
\hline Bottleneck: & Sequence & & Gene discovery & Valid'd targets & Clinical \\
\hline
\end{tabular}

Exhibit 10. Pre- and post-genomics/proteomics (Source: Banc of America Securities).

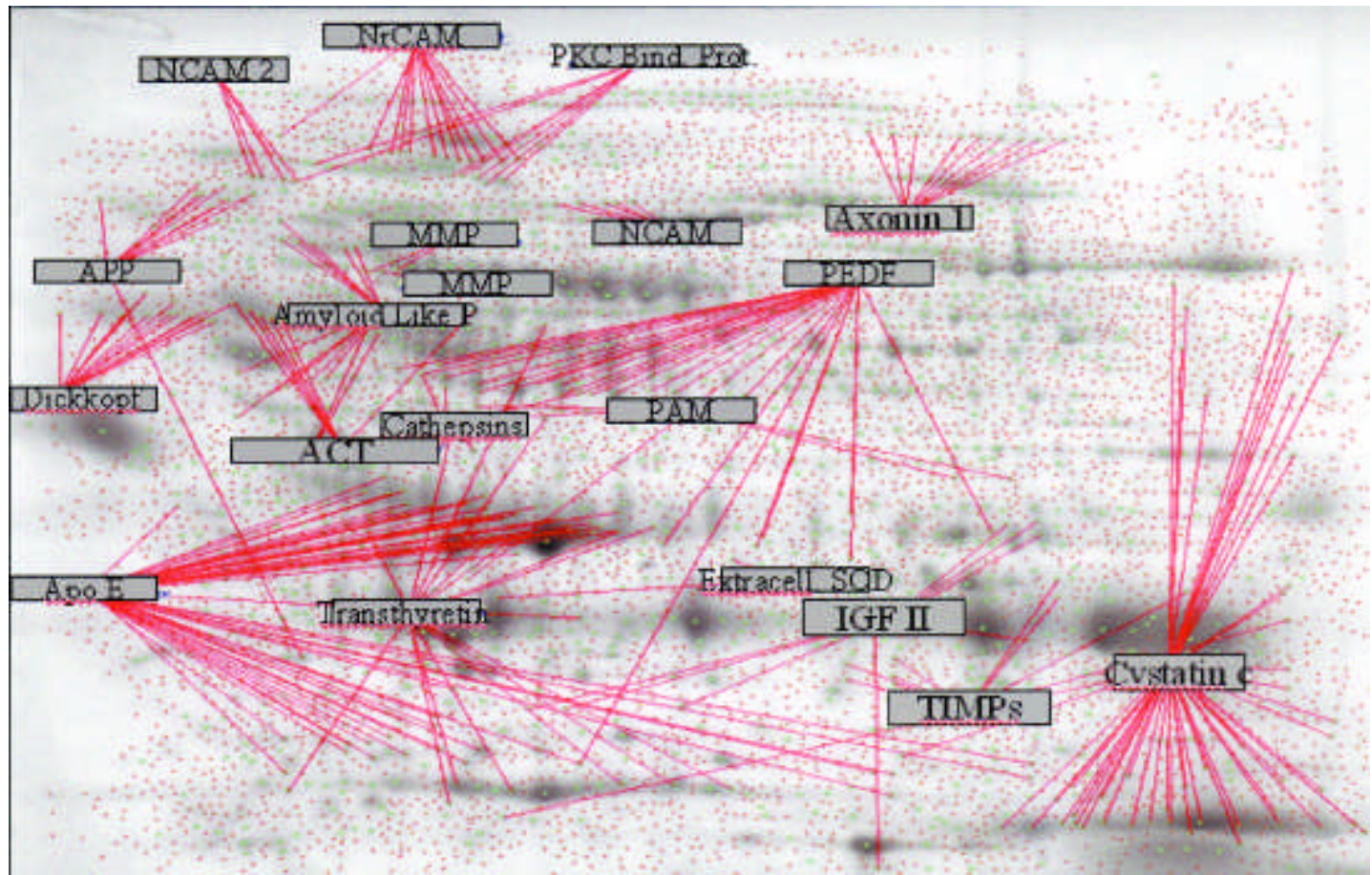

Exhibit 11. The hard wiring of the proteome. (Source: Banc of America Securities). 
light the relevance of proteomics to drug discovery and the pharmaceutical industry going forward.

Note that over the course of this paradigm, the number of characterized genes and targets for drug discovery has grown. Perhaps the most important challenge herein is the validation of targets and their usage/modulation for drug discovery and development. This is the domain of proteomics and underscores the importance of mining of data in the quest for the "deployment of the proteome." Exhibit 11 illustrates the key problem that functional proteomics seeks to address-the incredibly complex hard wiring of the proteome.

Exhibit 11 is a scan of a 2-D gel that illustrates how different proteins are linked in various situations (and therefore, pathways). This is a snapshot of the proteome at one moment in time and situation (normal or diseased). Under different stimuli, the proteome alters and different pathways are turned on. Computational proteomics seeks to identify these incredibly complex pathways by using IT tools and algorithms to mine these data.

\begin{tabular}{|lccccc|}
\hline & \multicolumn{2}{c}{ Market Size $($ in $\mathbf{\$ M})$} & \multicolumn{2}{c|}{ Market Share } & AGR \\
\cline { 2 - 6 } Technology & $\mathbf{2 0 0 0}$ & $\mathbf{2 0 0 6}$ & $\mathbf{2 0 0 0}$ & $\mathbf{2 0 0 6}$ & $\mathbf{2 0 0 0 - 2 0 0 6}$ \\
\hline MS for Proteomics & 215 & 886 & $43 \%$ & $44 \%$ & $27 \%$ \\
2D Gel Separation & 170 & 646 & $34 \%$ & $32 \%$ & $25 \%$ \\
Bioinformatics dbase & 25 & 102 & $5 \%$ & $5 \%$ & $26 \%$ \\
Cap. HPLC & 55 & 170 & $11 \%$ & $9 \%$ & $21 \%$ \\
Bioinformatics Tools & 20 & 104 & $4 \%$ & $5 \%$ & $32 \%$ \\
Emerging Technologies & 10 & 87 & $2 \%$ & $4 \%$ & $44 \%$ \\
Overall Market & 495 & 1995 & $100 \%$ & $100 \%$ & $26 \%$ \\
Source: U.S. Bancorp Piper Jaffray Equ. Res. May 2001 & & & & \\
\hline
\end{tabular}

Exhibit 12. Market opportunity in various proteomics sectors.

\begin{tabular}{|ll|}
\hline Company & Comments \\
\hline GeneFormatics, Inc. & $\begin{array}{l}\text { NMR, X-ray crystallography, and computational tools for structure and function } \\
\text { correlations }\end{array}$ \\
Inpharmatica, Ltd. & $\begin{array}{l}\text { Informatics platform for discovery of drug targets based upon protein sequence, } \\
\text { structure, and function } \\
\text { Integrative Proteomics, Inc. }\end{array}$ \\
Moltidisciplinary approach to proteomics \\
Structural Bioinformatics, Inc.) & Proprietary algorithms for 3-D structural work \\
Structural Bioinformatics, Inc. & Proprietary IT tools for proteomics (protein-surface analyses) \\
Structural GenomiX & Protein crystallography and high-throughput 3-D protein structure determination \\
SyrrX, Inc. & Protein crystallography and high-throughput 3-D protein structure determination \\
Protein Pathways, Inc. & IT tools for proteomics \\
Micromass (Division of Waters) & Automated high-throughput searching of protein and genomic databases with \\
BioBridge Computing & mass spectrometric data \\
Compugen & Protein identification IT tools \\
ProteoMetrics & Protein identification using mass spectrometric data \\
Thermo Finnigan & Protein identification IT tools \\
Bruker Daltonics & Correlation (IT) tools for mass spectra from protein or nucleotide databases \\
Applied Biosystems/MDS Sciex & IT tools for protein identification using mass spectrometry \\
& Protein identification, expression tools \\
\hline
\end{tabular}

Exhibit 13. Companies in the computational proteomics space (Source: Industry sources). 


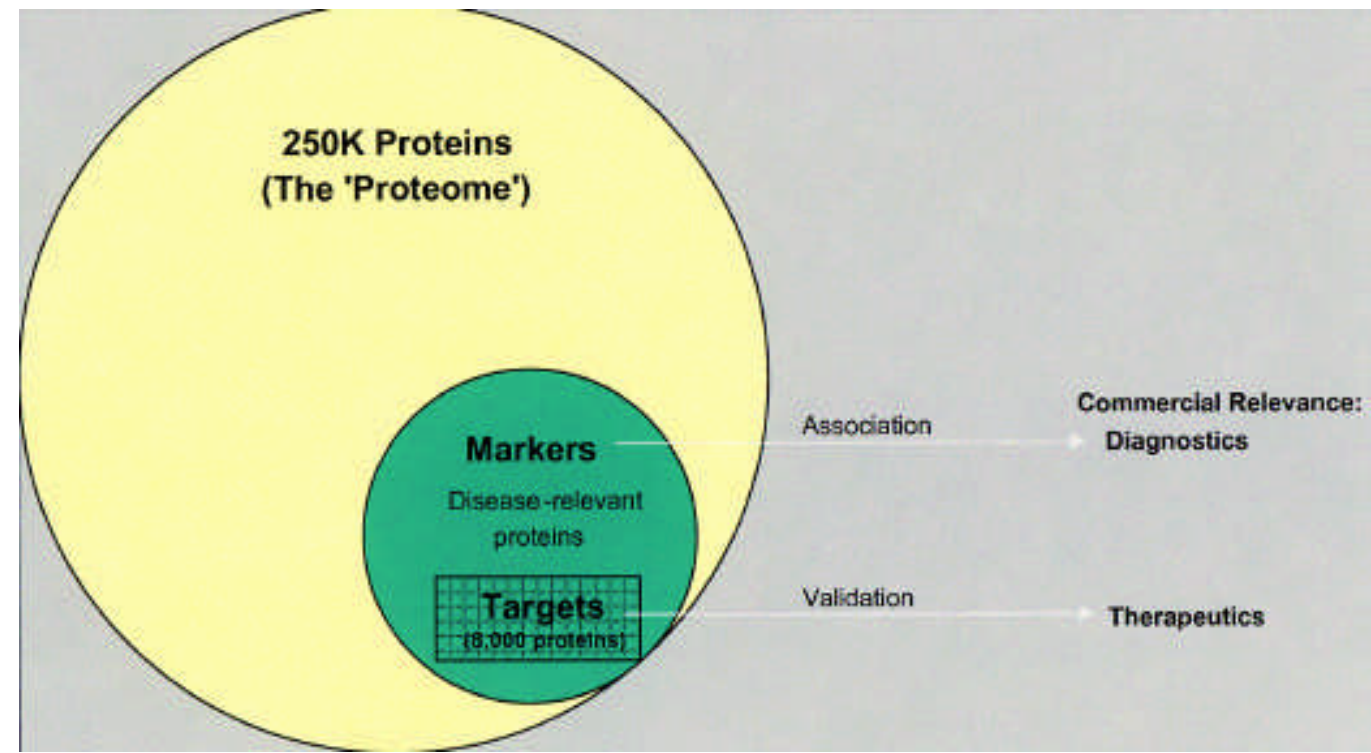

Exhibit 14. The functional proteome (Source: Banc of America Securities).

\section{MARKET OPPORTUNITIES IN THE VARIOUS PROTEOMIC SECTORS AND THE COMPETITIVE LANDSCAPE}

We focus in this section on some of the quantitative market analyses that seek to quantify the proteomics space. Exhibit 12 presents a breakout of the various sectors of proteomics, their relative sizes, and growth rates.

Note from Exhibit 12 how the growth of bioinformatics tools in proteomics is expected to be a brisk $32 \%$. Also note the growth in the database (information content) business. It is evident from the total life science IT market for drug discovery as well as the more proteomics-focused market opportunity that a growth opportunity lies in the deployment of computational (IT) tools and databases (content) in proteomics. From Exhibit 12 it is clear that the growth of IT tools for proteomics outperforms the overall growth of the proteomics market.

We have presented herein a market analysis of IT and proteomics and sought to define the various "bins" into which this opportunity segregates. In the future, new applications of proteomics in drug discovery and other sectors of life sciences will drive further the need for dedicated IT tools and databases that curate and mine the mass of information that has only recently begun to emerge as a result of the various public and proprietary efforts, not unlike the race to map the human genome.

The competitive landscape in computational proteomics is just getting formed. There is no established market leader and there are no market shares to talk about. At this early stage in the proteomics enterprise, companies are merely grabbing turf and figuring out business models later.

Exhibit 13 presents some selected proteomics companies that have a play in the computational proteomics space. Note that this is not an exhaustive list of all types of proteomics plays. We have deliberately sought to restrict ourselves here to the dedicat- ed entities that have defined their corporate focus in the elucidation of proteomics structures and pathways.

\section{CONCLUSION}

We have explored the IT market opportunity in the drug discovery sector in general, and then more specifically in the proteomics sector. We find a nascent market currently in this space and the possibility of aggressive growth. After all, the extraction of value from genomics requires proteomics, and proteomics requires sophisticated data mining to gain its full impact.

Genomics is finite-the genome is a fixed number of base pairs with a certain number of polymorphisms contained in it. Proteomics is potentially infinite with a huge number of possible "conformations" in which the proteome may present itself. The key is to extract biological value from the proteome-and this is the realm of computational proteomics.

We have not attempted in this article to provide a technology analysis of the proteomics landscape; that is beyond scope of this article. What we have aimed at is understanding the market potential that exists. We close with Exhibit 14 that presents schematically that the functional proteome, that fraction of the proteome that is usable in terms of discovery, must be teased out from the overall proteome (much of which is probably invariant in disease situations, anyway), and this argues for the need of IT tools to mine the proteome in the coming years.

Address correspondence to:

Enal Razvi

VP, Business Development

DiscoveRx Corporation

Fremont, CA 94538, USA

e-mail:erazvi@earthlink.net 